\title{
FUTSAL: TÁTICA DEFENSIVA CONTEMPORÂNEA E A TEORIA DE ENSINO DOS JOGOS ESPORTIVOS COLETIVOS DE CLAUDE BAYER
}

\author{
Marcelo Compagno Michelini, Universidade Estadual de Campinas - UNICAMP, \\ Campinas, São Paulo - Brasil \\ Renato Francisco Rodrigues Marques, Universidade de São Paulo - USP, Ribeirão Preto, \\ São Paulo - Brasil \\ Wilton Carlos de Santana, Universidade Estadual de Londrina - UEL, Londrina, Paraná - \\ Brasil \\ Gustavo Luiz Gutierrez, Universidade Estadual de Campinas - UNICAMP, Campinas, São \\ Paulo - Brasil
}

\section{RESUMO}

Este artigo tem o objetivo de inter-relacionar a teoria de ensino dos jogos esportivos coletivos de Claude Bayer e a tática defensiva contemporânea do futsal, de modo a levantar subsídios pedagógicos da primeira que pudessem contribuir para a compreensão tática da segunda, organizando-a didaticamente. Para tanto, foram analisados o livro "O ensino dos desportos colectivos", no qual Bayer apresenta os princípios operacionais defensivos comuns aos esportes coletivos e suas respectivas regras de ação, e publicações nacionais e internacionais especializadas, datadas a partir da década de 1990 que apresentassem um referencial tático defensivo sobre futsal. Foi possível construir uma reflexão sobre formas de compreensão tática de situações de defesa no futsal a partir dos princípios operacionais dos esportes coletivos propostos por Bayer. Acredita-se que este trabalho pode contribuir com avanços na pedagogia do esporte em relação à otimização de processos pedagógicos que objetivem promover a melhoria da compreensão tática de treinadores e jogadores de futsal.

Palavras-Chave: Esporte; Ensino; Tática; Futsal; Bayer.

\section{FUTSAL: CONTEMPORARY DEFENSIVE TACTICS AND TEACHING COLLECTIVE SPORTS THEORY OF CLAUDE BAYER}

\begin{abstract}
This paper aimed to inter-relate the teaching sports collective theory of Claude Bayer and futsal contemporary defensive tactic, in order to gather information of the first teaching that could contribute to the understanding of the second tactic, organizing it didactically. For this purpose, the book "The teaching of team sports," in which Bayer presents the operating principles common to the defensive team sports and their rules of action, and national and international specialized publications from the 1990 s to present a tactical reference defensive about futsal. It was possible to construct a reflection on ways of understanding situations of defense tactic in futsal from the operating principles of team
\end{abstract}

Conexões: revista da Faculdade de Educação Física da UNICAMP, Campinas, v. 10, n. 1, p. 20-37, jan./abr. 2012. ISSN: 1983-9030 
sports offered by Bayer. This paper can contribute to advancing the teaching of sport in relation to optimization of pedagogical processes aimed at promoting better understanding of the tactics of futsal coaches and players.

Key-Words: Sport; Teaching; Tactic; Futsal; Bayer.

\section{FÚTBOL SALA: TÁCTICAS DE DEFENSA CONTEMPORÁNEAS Y LA TEORÍA DE LA ENSEÑANZA DE LOS DEPORTES COLECTIVOS DE CLAUDE BAYER}

\section{RESUMEN}

Este artículo tiene como objetivo interrelacionar la teoría de la enseñanza de los deportes colectivos de Claude Bayer y la táctica defensiva contemporánea del fútbol sala, con el fin de recabar información de la primera enseñanza que podrían contribuir a la comprensión de la segunda táctica, la organización de la didáctica. Para ello, el libro "La enseñanza de los deportes de equipo", en el que Bayer presenta los principios de funcionamiento comunes a los deportes de equipo a la defensiva y sus normas de acción, publicaciones nacionales y internacionales especializadas a partir de la década de 1990 para presentar una referencia táctica la defensiva acerca de futbol sala. Fue posible construir una reflexión sobre las formas de entender las situaciones de defensa táctica en el fútbol de los principios de funcionamiento de los deportes de equipo que ofrece Bayer. Se cree que este trabajo pueda contribuir a promover la enseñanza del deporte en relación con la optimización de los procesos pedagógicos encaminados a promover una mejor comprensión de las tácticas de los entrenadores de fútbol y jugadores.

Palabras-Clave: Deporte; Enseñanza; Tactica; Futbol Sala; Bayer 


\section{INTRODUÇÃO}

Para que um sujeito possa participar ativamente de um jogo esportivo coletivo (JEC) é fundamental que realize reflexões táticas e saiba tomar decisões pautadas nas situações que o jogo lhe oferece. Para tal, deve conhecer a estrutura tática da modalidade e compreender as razões de determinadas ações ${ }^{1}$. Tal estrutura diz respeito à lógica interna dos JEC, que contempla suas diferentes fases ou momentos: ataque, transição defensiva, defesa, transição ofensiva ${ }^{2}$.

Com o intuito de guiar as equipes em relação as suas pretensões táticas, Claude Bayer estabeleceu alguns princípios que servem como ponto de partida para o ataque e a defesa, nomeados de "princípios operacionais". Além destes, criou as chamadas "regras de ação" ou de comportamento, que dariam sustentação àqueles.

O objetivo deste estudo é inter-relacionar o conhecimento tático defensivo contemporâneo do futsal com a obra do autor francês, abstraindo, desta última, subsídios pedagógicos que contribuíssem para o ensino/treino tático da modalidade, de modo a organizá-lo didaticamente, buscando facilitar a contextualização e compreensão dos conteúdos do jogo por parte dos jogadores.

Portanto, a pergunta que se pretende responder neste estudo é: existe relação entre os princípios operacionais dos jogos esportivos coletivos (JEC), propostos por Claude Bayer, e o conhecimento tático a respeito de conteúdos defensivos no futsal?

As contribuições deste trabalho se fazem úteis, pois oferecem subsídios teóricometodológicos para o planejamento e atuação pedagógica em relação à iniciação e o treinamento defensivo de equipes de futsal; explora uma teoria geral dos JEC e identifica particularidades de uma modalidade específica, norteando sua compreensão.

O método de realização deste trabalho se compõe em análise de referencial teórico e posterior reflexão sobre particularidades do objeto analisado. Inicialmente, são descritos pressupostos teóricos da teoria de Claude Bayer sobre o ensino de JEC. Posteriormente, são apresentados alguns conceitos táticos defensivos próprios do futsal e, como finalização

Conexões: revista da Faculdade de Educação Física da UNICAMP, Campinas, v. 10, n. 1, p. 20-37, jan./abr. 2012. 
do trabalho, são realizadas reflexões e conexões entre tais conteúdos e sua lógica de ocorrência com base nos princípios operacionais.

\section{A TEORIA DE CLAUDE BAYER: INVARIANTES, PRINCÍPIOS OPERACIONAIS E REGRAS DE AÇÃO}

Bayer estabelece em sua teoria de ensino dos JEC uma lógica comum aos mesmos. Assim sendo, bastaria ao jogador compreender os princípios operacionais e aplicar as regras de ação de uma modalidade esportiva para aprender a jogar outras.

Para sustentar a similaridade entre diferentes JEC, Bayer ${ }^{3}$ afirma que todos contemplam seis características comuns, chamadas de constantes ou invariantes, que configurariam uma modalidade esportiva coletiva:

- Bola ou implemento central: esférica ou oval, as regras da modalidade determinarão como esta deverá ser manipulada;

- Terreno demarcado: dentro do qual se desenvolverá a partida;

- Alvo a atacar e alvo a defender: objetivo da modalidade, marcar o ponto e procurar impedir o adversário de pontuar;

- Parceiros: ajudam na progressão da bola e na defesa do alvo;

- Adversários: estes devem ser vencidos para a marcação do ponto;

- Regras do jogo: devem ser respeitadas.

Não resta dúvida de que essa teoria influenciou Garganta, ${ }^{4}$ ao ponto deste afirmar que existem denominadores comuns a determinados JEC, o que possibilitaria agrupá-los e potencializar o processo ensino-aprendizagem. Por conseguinte, há certa proximidade entre as modalidades esportivas coletivas; existem elementos táticos comuns para um atleta de basquete e outro de futsal. Por exemplo, para ambos, criar linhas de passe é um comportamento tático similar. Outro denominador comum em ambas as modalidades seria o jogo de transição, quando a equipe se encontra em mudança de atitude, de função tática (ataque-defesa/defesa-ataque), reposicionando-se. ${ }^{5}$ Assim também acontece no handebol, no hóquei, no pólo aquático, etc. 
O fato é que os JEC são jogos de cooperação-oposição, isto é, duas equipes, com o mesmo objetivo, se opõem durante uma partida de modo a medirem forças na tentativa de superar o esforço do oponente. ${ }^{6}$ A tentativa de superá-lo é pautada no alcance de um alvo em terreno adversário. Esta conquista pode ser feita através da invasão do terreno ou lançando o implemento central para perto do alvo oponente (cesta, baliza, entre outras formas). Ainda em algumas modalidades, como o beisebol, por exemplo, afastando a bola do terreno de jogo para a conquista do mesmo. E no caso de modalidades como o vôlei ou o tênis, que são jogos em que o espaço é separado e a participação dos jogadores alternada, lançando-a sobre o terreno adversário. Por outro lado, a equipe que defende seu alvo deverá criar maneiras de se opor aos eventuais ataques adversários, gerando assim a característica central dos JEC, a complexidade entre cooperação e oposição. ${ }^{6}$

Outros elementos em comum entre modalidades coletivas podem ser encontrados: marcação atrás da linha da bola, marcação individual, marcação pressão, desmarcações, coordenação de ações ofensivas, entre outras. Embora sejam encontradas semelhanças, alguns detalhes podem ser diferentes, pois as regras do jogo, a dimensão espacial, o implemento central, se alteram de uma modalidade para a outra, com isso, se modifica a dinâmica do jogo. Quer isso dizer que uma opção tática defensiva no handebol, futsal ou basquete pode ser marcar a partir da meia-quadra defensiva, de forma zonal, individual ou combinada, mas apresentará, certamente, algumas diferenças, devido às regras, quadras e bolas. Porém, a lógica, o porquê fazer, continua semelhante para essas modalidades.

Os fatores principais de diferenciação entre as modalidades coletivas são suas regras específicas. Estas que irão conferir as particularidades, o que é permitido fazer para se marcar o ponto e para tentar impedir a marcação do mesmo. As regras direcionam a modalidade coletiva para o jogo de cooperação-oposição, ao mesmo tempo em que impõem normas de ação que variam de uma modalidade para outra. ${ }^{7}$

O regulamento possui uma lógica intrínseca que marca os requisitos necessários para o desenvolvimento da ação de jogo que determina em parte a lógica interna do esporte que regula. Não é possível um esporte sem regras, estas constituem uma dimensão lingüística da qual não se pode escapar e condicionam, em larga medida, a atuação do jogador. ${ }^{8}$ 
Bayer $^{3}$ define seis princípios operacionais comuns aos JEC (Quadro 1). Trata-se de formas de ação que norteiam o ato de jogar coletivamente, dão sentido ao jogo e formam a lógica central de sistemas, estratégias, padrões e intenções durante uma partida. Existem com base nas regras e exigências de realização impostas por esses jogos.

Quadro 1 - Princípios comuns aos JEC

\begin{tabular}{ll}
\hline \multicolumn{1}{c}{ ATAQUE } & \multicolumn{1}{c}{ DEFESA } \\
\hline Conservação da bola & Recuperação da bola \\
$\begin{array}{l}\text { Progresão dos jogadores e da bola até a } \\
\text { meta adversária }\end{array}$ & Impedir a progressão dos jogadores \\
Atacar a meta adversária & e da bola até a minha meta \\
\hline
\end{tabular}

Fonte: Adaptado de Bayer, ${ }^{3}$ p. 47.

Estes princípios representam a origem da ação e definem as propriedades invariáveis sobre as quais se vai unir a estrutura fundamental do desenvolvimento dos acontecimentos. ${ }^{3}$ Portanto, toda tática individual e coletiva de uma equipe, de acordo com essa teoria, deveria pautar-se sobre esses princípios operacionais.

Pode-se perceber ainda, que os princípios operacionais são antagônicos, isto é, cada um dos princípios de ataque tem um correspondente defensivo que tem por objetivo anulá-lo. A tendência durante o transcorrer de uma partida é que esses princípios se anulem e estabeleçam equilíbrio de forças.

Os princípios operacionais descritos por Bayer $^{3}$ se relacionam entre si, isto é, para o sucesso da ação coletiva de ataque ou defesa todos são igualmente importantes, não havendo hierarquia. Por exemplo: para proteger a baliza seria relevante, mas não essencial, que a equipe defensora impedisse o adversário de invadir seu campo, uma vez que perto da baliza a finalização ficaria muita favorecida. Da mesma forma, para se manter a posse de bola, por vezes os atacantes devem eleger regredir no terreno de jogo, pois quanto mais perto da meta, mais se intensifica a defesa. Logo, insistir em atacar apressadamente, sem selecionar o que se faz, poderia implicar em sucessivas perdas da posse de bola e, consequentemente, num jogo com muitas chances de contra-ataques e transições seguidas.

Conexões: revista da Faculdade de Educação Física da UNICAMP, Campinas, v. 10, n. 1, p. 20-37, jan./abr. 2012. 
Por conseguinte, não é possível determinar uma ordem de importância desses princípios. Faz-se necessário considerá-los como componentes da construção da tática coletiva e atitudes individuais ofensivas e defensivas durante uma partida.

Em cada modalidade esportiva coletiva é possível encontrar especificidades. Tais processos variam de acordo com os princípios operacionais, porém se expressam de diferentes maneiras, de acordo com as formas do jogo em questão. Disso tratam as regras de ação, que seriam os modos de os jogadores sustentarem os princípios operacionais, respondendo às demandas situacionais apresentadas continuamente no decorrer de uma partida. Para Bayer ${ }^{3}$ (p.48),

O jogador, em ação, aplicando os princípios operacionais comuns aos esportes coletivos, adaptando-os continuamente à realidade das situações do terreno, vai apelar a fatores de execução, quer dizer, meios de sistemática de base, para poder intervir de maneira eficaz e resolver os problemas postos.

Entre as modalidades coletivas existem diferenças, explicitadas pelas regras de ação, que lhes dão especificidade. Trata-se de variantes dos princípios operacionais e mudam de modalidade para modalidade. Isso porque são as regras de cada esporte que lhe conferem a maneira adequada e permitida de agir.

A aplicabilidade das regras de ação está diretamente relacionada à capacidade de tomada de decisão de um determinado atleta que, por sua vez, está relacionada ao seu entendimento da lógica do jogo e de sua capacidade de realização motora. Por isso, Garganta $^{4}$ refere que a forma de atuação de um jogador está fortemente condicionada ao modo como ele percebe o jogo. Por extensão, um atleta não cogitará tal resposta para uma determinada situação se esta não estiver inserida na sua capacidade de jogo.

Logo, para compreender determinada modalidade esportiva com base na teoria de Bayer, é necessário identificar os princípios operacionais na mesma, e ainda, estabelecer suas especificidades em relação às regras do jogo e de ação para, num terceiro momento, sistematizar seu processo de ensino/aprendizagem. Daí a necessidade de nos reportarmos ao futsal.

Conexões: revista da Faculdade de Educação Física da UNICAMP, Campinas, v. 10, n. 1, p. 20-37, jan./abr. 2012. 


\section{O CONTEÚDO TÁTICO DEFENSIVO DO FUTSAL E AS INTER- RELAÇÕES DE SUAS REGRAS DE AÇÃO COM OS PRINCÍPIOS OPERACIONAIS DE CLAUDE BAYER}

O fato de o futsal ser uma modalidade esportiva baseada em cooperação e oposição, no qual os jogadores, num espaço comum e padronizado, porém dinâmico, podem agir simultaneamente sobre a bola, ${ }^{8}$ faz com que o jogo apresente variações táticas de realização, ou seja, diferentes formas de tomadas de decisão e ação coletivas e/ou individuais, visando o alcance da meta adversária.

Para a compreensão da complexidade desse jogo, se faz necessário estabelecer categorias. O jogo de futsal pode ser dividido em quatro momentos principais: o ataque, a defesa, a transição ofensiva e a transição defensiva. Estes interagem durante a realização de uma partida e, por isso, não podem ser completamente dissociados. ${ }^{9}$

Deste modo, para exposição do conteúdo tático defensivo do futsal a ser analisado neste trabalho, buscando uma associação com a teoria de Claude Bayer, tem-se a análise de momentos de defesa e de transição defensiva, num sentido de realizar conexões entre tais conteúdos e a teoria do autor francês, contextualizando as especificidades do futsal com base na obra do autor.

Embora comumente a defesa comece quando da perda da bola, Bayer ${ }^{3}$ (p.99) alerta que esta se inicia durante o ataque, quando os jogadores procurariam "[...] assegurar o equilíbrio ofensivo por suportes, prever a resposta do adversário". Desta forma, a defesa agiria "para não cair numa situação de inferioridade operacional, logo que a equipe perca a posse de bola".

Bayer $^{3}$ entende que toda a ação defensiva deveria obedecer aos três princípios operacionais de defesa, sendo que toda ação tática implícita ao jogo é realizada a partir de uma leitura das intenções dos participantes. Neste sentido, os princípios revelam-se importantes para a construção dos posicionamentos, dos conceitos e dos sistemas de marcação, na medida em que todas as intenções táticas individuais e coletivas se sustentam em suas diretrizes e são aplicadas através das regras de ação.

Conexões: revista da Faculdade de Educação Física da UNICAMP, Campinas, v. 10, n. 1, p. 20-37, jan./abr. 2012. ISSN: 1983-9030 
Bayer $^{3}$ apresenta três regras de ação defensivas: marcação ativa, agir continuamente e ajuda. Na "marcação ativa", o marcador deve sempre "agredir" seu adversário; deve ter uma postura que o incomode e, desta maneira, induzi-lo a tomar decisões precipitadas que acabem por forçar o erro e a conseqüente perda da posse de bola. Na "agir continuamente", o marcador deve sempre estar atento à bola e a todas as possibilidades e movimentações do ataque; igualmente, procurar obter qualquer tipo de "informação" do ataque para poder antecipar ou chegar mais próximo ao adversário; deve realizar tudo isso sem deixar sua função defensiva determinada pelo tipo de marcação empregado. O significado da "ajuda" está na essência dos JEC, pois quando um colega de equipe falha existe a necessidade de se fazer uma cobertura. Por outro lado, se um colega obtém tanto sucesso de modo a atrasar em muito o ataque, ou induzi-lo a um espaço lateral na quadra, por exemplo, abre-se a oportunidade da dobra de marcação.

O jogo de futsal se caracteriza por ser eminentemente informativo. ${ }^{10}$ Quer isso dizer que as ações dos jogadores são repletas de significado. Neste contexto informacional, os defensores, a fim de retomar a posse da bola, enfrentarão as situações com os seus recursos, isto é, com sua bagagem de experiências anteriores. Qualquer tentativa malsucedida poderá causar uma situação favorável ao ataque. Por isso, pode-se dizer que é grande a responsabilidade tático-cognitiva do defensor. É exatamente neste ponto que as regras de ação encontram sua efetividade, pois estas sustentariam os princípios operacionais defensivos ${ }^{3}$.

A primeira atitude de qualquer equipe quando perder a posse de bola deve ser a de impedir o contra-ataque. Para isso, os jogadores devem se posicionar de forma a atrasar a evolução contrária e logo estar com a defesa postada e todos os atacantes marcados. A defesa de contra-ataque, que corresponde ao jogo de transição defensiva, seria sustentada por duas atitudes táticas principais: o retorno defensivo, quando os defensores correm para a sua meia-quadra e se agrupam, e a temporização, quando um jogador simula atacar o portador da bola e se desloca rapidamente para a sua meta, não se decidindo de forma clara nem por uma situação (atacar a bola), nem por outra (retornar à defesa). Ao fazer isso, consegue que os atacantes duvidem do que fazer, e é exatamente isso que permite a organização defensiva de seus companheiros. ${ }^{11}$ 
Tal organização, se associada à teoria de Bayer, pode ser compreendida com o equilíbrio obtido no posicionamento da defesa, de modo a facilitar ações que garantam os princípios operacionais. Uma postura defensiva eficiente nesta leitura seria aquela que privilegia a equipe que atua protegendo sua meta e seu território, de modo a levar vantagem sobre quem tem a posse de bola e tenta aplicar os princípios operacionais de ataque.

Outro conceito característico de processos de defesa no futsal é o de indução do ataque, ou seja, posturas defensivas que impedem o atacante de explorar certos espaços de quadra, oferecendo pontos tidos como menos perigosos. Trata-se de uma vantagem posicional, relacionada ao território 5 . Por exemplo, proteger o meio, favorecendo finalizações e progressões nas laterais da quadra, com menor ângulo em relação à meta. ${ }^{7}$

Do mesmo modo, pode-se citar o respeito à linha da bola, que se trata de uma linha imaginária que passa sobre a bola em sentido perpendicular à lateral da quadra. ${ }^{12} \mathrm{O}$ jogador que está atrás da linha da bola ocupa espaços preciosos, que seriam tomados pelo adversário $^{2}$. Portanto, ao se ocupar o espaço entre a bola e a meta defendida, a defesa dificultaria passes para frente, dificultando tanto a progressão como a finalização à meta, dois dos princípios operacionais do ataque. Busca garantir, ao menos, a igualdade numérica entre atacantes e defensores entre a bola e o gol.

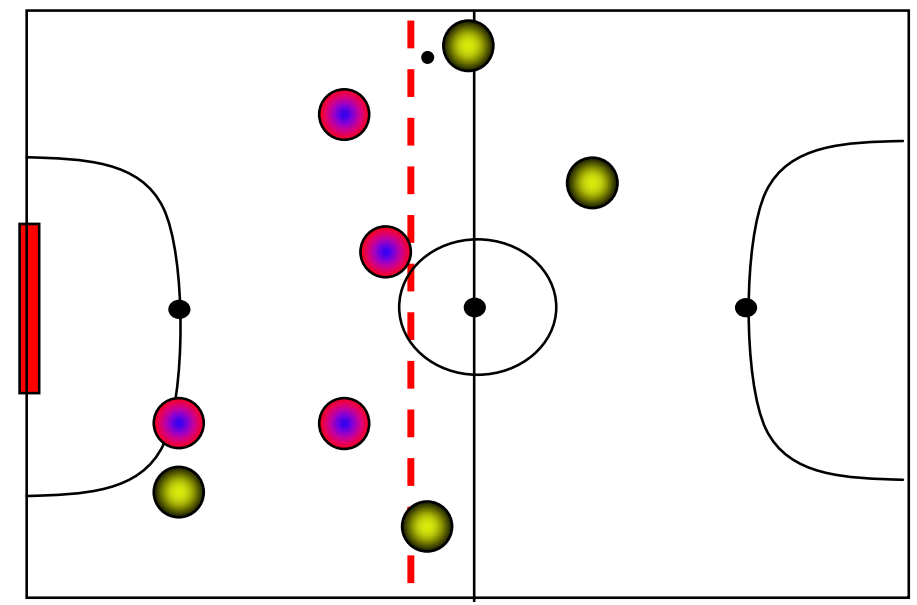

Figura 1. Linha da bola.

Conexões: revista da Faculdade de Educação Física da UNICAMP, Campinas, v. 10, n. 1, p. 20-37, jan./abr. 2012. 
Pode-se citar ainda, alguns referenciais utilizados para organização tática do jogo de futsal $^{7}$ :

- Linha imaginária central: divide-se a quadra em duas partes, esquerda e direita; a defesa deve-se postar com base nesse referencial, de maneira a proteger a meta; o meio da quadra deve ser ocupado, levando os adversários a utilizarem as laterais da quadra, ficando com um ângulo reduzido, dificultando assim os passes e a finalização. Esta norma de ação respeita o princípio operacional de defesa da meta e, principalmente, de impedimento da progressão do adversário em seu campo, induzindo-o a manter a posse de bola em locais mais distantes ou menos favoráveis à finalização.

- Meta a ser defendida: Existe um defensor para cada atacante (caso não haja expulsão). Deste modo, respeitando os princípios operacionais, cada defensor deve se colocar entre o seu atacante direto e a meta que defende. Se toda equipe fizer isso, qualquer adversário que tenha a posse de bola sempre encontrará um marcador entre ele e a meta que ataca. Essa ação também respeita a idéia de impedimento de avanço do adversário em seu campo e, consequentemente, de proteção da meta.

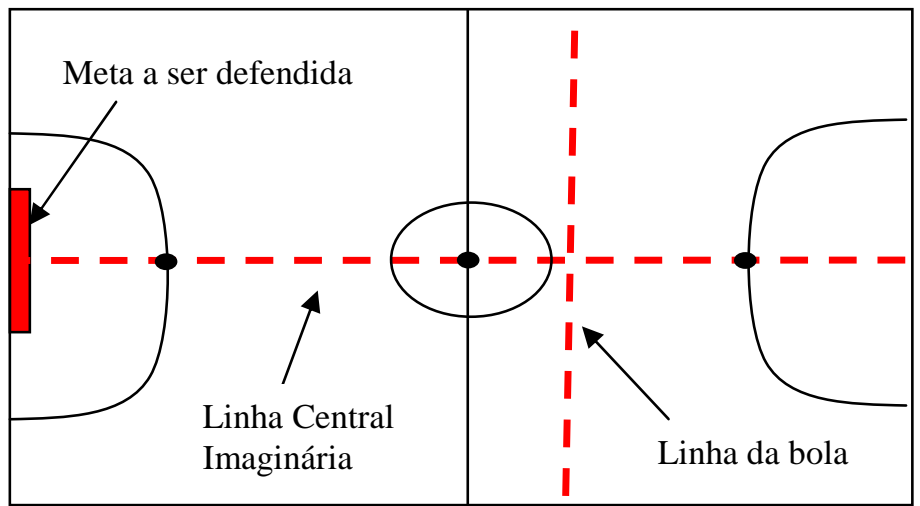

Figura 2: Referenciais de defesa na quadra.

Tais conceitos têm sua essência nos princípios operacionais de proteção da meta e impedimento da progressão adversária sobre seu terreno de jogo. A simples utilização das ações de "indução" e "linha da bola", por exemplo, de modo meramente analítico e aplicativo pode ser insuficiente para a compreensão e utilização destas por parte de um jogador. 
A contextualização baseada nos princípios operacionais propostos por Claude Bayer pode direcionar tais ações de modo potencializado, visto que a partir dela o sujeito compreende as razões de tais formas de posicionamento e deslocamento, facilitando suas tomadas de decisão frente às diferentes situações de jogo.

Há no futsal diversas maneiras de se postar a equipe em quadra, que variam conforme a intenção tática coletiva da equipe. Algumas dessas determinações são as linhas de marcação, referenciais previamente definidos que delimitam o espaço ocupado pela marcação. Uma vez definidas tais linhas, os defensores se postarão entre a mesma e a meta defendida, para dar início à ação de defesa.

Essa referência comporia parte do sistema defensivo, determinando áreas de quadra nas quais os defensores começariam a abordar os adversários. Seriam quatro as linhas de marcação ${ }^{2}$ : linha 1 (marcação na quadra toda); linha 2 (marcação em 3/4 de quadra); linha 3 (marcação em meia-quadra); linha 4 (marcação em 1/4 de quadra).
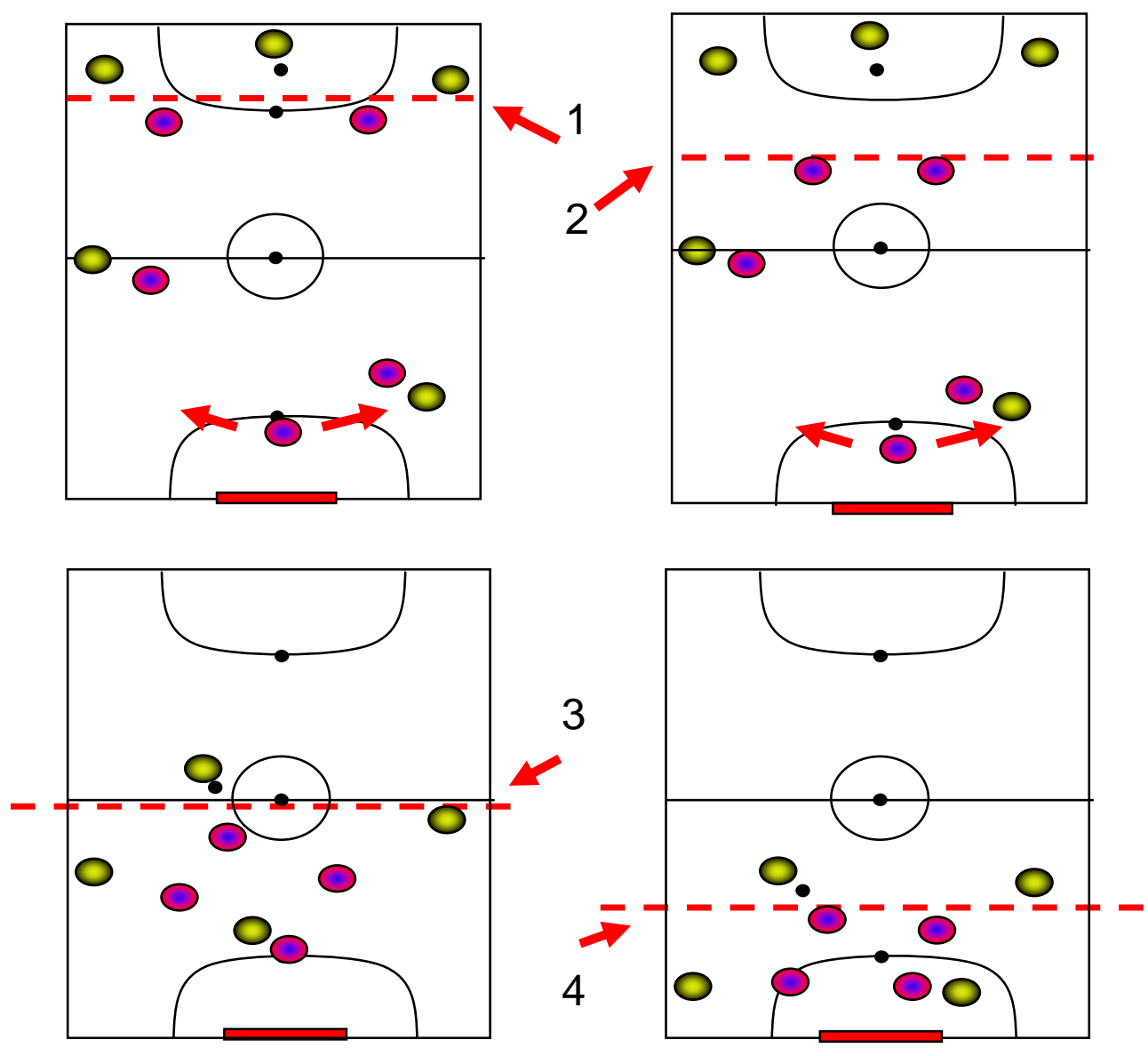

Figura 3: Linhas de marcação.

Conexões: revista da Faculdade de taucaçao rısıca aa uivıcaivır, Lampınas, v. ıU, n. 1, p. 20-37, jan./abr. 2012. 
Uma informação importante a respeito das linhas defensivas é observar o espaço que existe entre os defensores. Na linha 1 este é grande, porém diminui na medida em que as linhas se aproximam da meta defendida. Essa aproximação entre os jogadores tende a facilitar a cobertura, no caso de algum desequilíbrio defensivo momentâneo. Por outro lado, quanto mais avançada a defesa, mais difícil será executá-la, em função da distância entre os defensores e do maior espaço para ações ofensivas. Porém, quanto mais avançada a marcação, maior é a chance de recuperar a posse de bola mais perto da meta adversária, e ter uma transição de contra-ataque mais curta e rápida.

Uma vez a equipe postada em quadra, há a necessidade de se saber qual o tipo de marcação que está sendo utilizado. A defesa no futsal se utiliza, principalmente, de três tipos de marcação: a) individual b) zonal e c) combinada (mista). Bayer ${ }^{3}$ (p.99) comenta sobre os dois primeiros tipos de defesa e suas principais características:

A defesa à zona privilegia o elemento bola, porquanto todos os adversários se deslocam em função dela (flutuação), sem negligenciar, no entanto, o adversário [...]. A defesa homem a homem preconiza uma defesa centrada principalmente no indivíduo, quer seja ou não o portador da bola, que pode, de acordo com a importância dada ao elemento bola, evoluir para uma defesa homem a homem com flutuação e troca.

Importante ressaltar que o autor chama a atenção para que qualquer que seja o tipo de defesa adotada pela equipe, os princípios operacionais continuam válidos. Para ele, ${ }^{3}$

[...] se as intenções verificadas são diferentes, as atitudes continuam idênticas, e os princípios operacionais igualmente válidos, tanto para marcações individuais, como para a defesa por zona (p.100).

À luz dos princípios operacionais e do entendimento lógico da modalidade, os tipos de marcação podem ser interpretados da seguinte maneira ${ }^{3}$ :

Marcação individual: cada jogador deverá marcar um adversário, acompanhando-o pelo espaço da quadra. Vale para esse tipo a noção de posicionamento defensivo já citado, uma vez que cada defensor deve procurar se posicionar de acordo com quatro referenciais: a linha imaginária no meio da quadra, a meta a ser defendida, a linha da bola e a linha de marcação. Esse tipo preconiza uma atenção especial sobre um adversário. Enquanto o defensor pensa em se posicionar e realizar a marcação impedindo que o atacante jogue, este tentará se desmarcar. É importante que o defensor mantenha uma distância segura

Conexões: revista da Faculdade de Educação Física da UNICAMP, Campinas, v. 10, n. 1, p. 20-37, jan./abr. 2012. 
com relação ao adversário, de modo que possa perceber suas intenções e não seja surpreendido por qualquer atitude que o supere, como por exemplo, uma corrida de um adversário fora de seu campo de visão ou uma "finta", isto é, uma mudança brusca de direção.

Marcação por zona: cada jogador deve se posicionar levando em consideração o posicionamento da bola e um respectivo espaço em quadra que será de sua responsabilidade naquele momento na jogada. Neste tipo se deve procurar ocupar os espaços considerados mais perigosos, isto é, pode-se procurar congestionar o meio da quadra para impedir qualquer tipo de ação do ataque no setor, ou ainda que algum atacante receba a bola neste espaço. Torna-se importante para o sucesso da ação defensiva por zona respeitar os referenciais de marcação e a rápida definição das zonas de responsabilidade na defesa, que dependem do posicionamento da bola e da atitude de dificultar ações pelo meio da quadra principalmente, cumprindo assim os princípios operacionais ${ }^{7}$ Tal ação faz sentido levando em conta que ações próximas às linhas laterais da quadra são dificultadas para o atacante, devido sua posição em relação à meta a ser alcançada e limites de ação.

Ressalta-se que durante uma partida as zonas de responsabilidade se alternam tendo em vista o posicionamento da bola, que percorre o meio da quadra e as alas na mesma jogada. Portanto, o defensor deve atentar-se a isso e procurar se posicionar reconhecendo o mais rápido possível sua zona de responsabilidade e, a partir disso, cumprir suas funções.

Outro ponto que merece atenção é o fato de que na defesa zonal, por existirem os setores previamente definidos e tendo em vista a dinâmica do jogo ofensivo, que contempla trocas de posições contínuas entre os atacantes a fim de progredir, manter a posse de bola e finalizar, os defensores podem ou não acompanhá-los, ou seja, fazer ou não a "troca de marcação". Esta última acontece frequentemente em jogos de futsal e se aplica quando um defensor percebe que é possível deixar o seu marcador e passar a marcar outro atacante sem que isso implique em desvantagem para a sua equipe. ${ }^{2}$ 
Marcação combinada (mista): esse tipo de defesa mistura a marcação individual com a zona, de modo que um ou mais jogadores recebam marcação individual e os demais zonal. A definição das zonas de responsabilidade, as trocas de marcação, os referenciais defensivos para se posicionar em quadra, entre outros, são válidos nessa defesa, que exige dos atletas saberem marcar de forma individual e por zona ${ }^{7}$. Para Lozano Cid et al. ${ }^{11}$ (p.170), a defesa mista "pode desestabilizar a equipe adversária, já que não está acostumada a que se defenda assim e terá que buscar alternativas de ataque".

As situações defensivas, independentemente da linha de marcação, formas de indução, sistemas individual, zonal ou misto, respeitam, em primeira instância, aos princípios operacionais de Bayer e, num segundo momento, a tais regras de ação específicas do futsal. Isso implica num processo de construção de componentes táticos que se baseia numa compreensão sistemática desses conceitos para a execução dessas ações no jogo.

\section{CONSIDERAÇÕES FINAIS}

A teoria de Claude Bayer propõe uma caracterização das modalidades esportivas coletivas de modo a oferecer uma possibilidade de compreensão de suas componentes táticas com base num ponto de partida comum. O conhecimento tático em futsal pode ser compreendido como produto dos princípios operacionais propostos pelo autor francês, aplicados de modo específico na modalidade.

Por exemplo, a ação ligada ao posicionamento atrás da linha da bola em situações defensivas respeita tanto o princípio de proteção da meta, quanto o de dificultar a progressão dos adversários.

Logo, é possível afirmar que a teoria de Claude Bayer pode ser aplicada como forma de referencial teórico para a compreensão do jogo de futsal e desenvolvimento de formas de ensino e treinamento desta modalidade. Os princípios operacionais propostos por ele

Conexões: revista da Faculdade de Educação Física da UNICAMP, Campinas, v. 10, n. 1, p. 20-37, jan./abr. 2012. 
contribuem no sentido de contextualizar ações táticas e sustentarem diretrizes de modo a facilitar a compreensão do jogador a respeito das variantes defensivas do jogo.

A compreensão e utilização dos princípios operacionais num processo de aprendizagem e treinamento do futsal acabam sendo pontos iniciais de grande valia, pois traduzem, de certo modo, a essência tática de modalidades esportivas coletivas. Do mesmo modo, aprofundamentos táticos num processo de especialização na modalidade podem também ser baseados em tais diretrizes.

Embora os conceitos descritos neste trabalho possam ser ensinados/treinados para um jogo defensivo eficiente de futsal, não se pode descartar a possibilidade de tomada de decisão individual do jogador e a eventual saída desses sistemas por parte dele, sendo esta também uma opção tática, desde que embasada numa forma de compreensão de jogo que considere princípios para realização.

Por isso, é importante salientar que o aprendizado tático defensivo está vinculado também à perspectiva de ação técnica. Ou seja, as ações motoras dos jogadores devem ser aprendidas e treinadas a partir da resolução de problemas e execução de princípios operacionais, facilitando o aprendizado ${ }^{4}$.

Estabelecem-se, neste processo, subsídios teóricos com a finalidade de enriquecer o campo de conhecimento sobre futsal e auxiliar professores e técnicos com uma perspectiva voltada à melhor entendimento sobre essa modalidade e de oferecimento de parâmetros para estimular a compreensão sobre o jogo entre praticantes.

Conexões: revista da Faculdade de Educação Física da UNICAMP, Campinas, v. 10, n. 1, p. 20-37, jan./abr. 2012. ISSN: 1983-9030 


\section{REFERÊNCIAS}

${ }^{1}$ FERREIRA, H. B.; GALATTI, L. R.; PAES, R. R. Pedagogia do esporte: considerações pedagógicas e metodológicas no processo de ensino-aprendizagem do basquetebol. In: PAES, R. R.; BALBINO, H. F. (Org.). Pedagogia do esporte: contextos e perspectivas. Rio de Janeiro: Guanabara Koogan, 2005. p. 123-136.

${ }^{2}$ SANTANA, W. C. Futsal: apontamentos pedagógicos na iniciação e na especialização. 2. ed. Campinas: Autores Associados, 2008

${ }^{3}$ BAYER, C. O ensino dos desportos colectivos. Lisboa: Dinalivros, 1994

${ }^{4}$ GARGANTA, J. Para uma teoria dos jogos desportivos colectivos. In: GRAÇA, A.; OLIVEIRA, J. (Org.). O ensino dos jogos desportivos. 2. ed. Porto: Universidade do Porto, 1995.

${ }^{5}$ CHAVES CHAVES, J. L.; RAMÍREZ AMOR, J. A. Táctica y estratégia en fútbol sala: situaciones de ataque y defensa. Barcelona: Hispano Europea, 1998.

${ }^{6}$ MARQUES, R. F. R.; SUGUIHURA, F. M. Beisebol: uma caracterização a partir dos princípios operacionais de Claude Bayer. In: CONGRESSO BRASILEIRO DE CIÊNCIAS DO ESPORTE, 14. Porto Alegre, 2005. Anais... Porto Alegre; CBCE, 2005. v. 1. p. 294.

${ }^{7}$ MICHELINI, M. C. Teoria de esportes coletivos de Claude Bayer: o futsal. 2007. Trabalho de Conclusão de Curso (Graduação em Educação Física) - Faculdade de Educação Física, Universidade Estadual de Campinas, Campinas, 2007.

${ }^{8}$ HERNÁNDEZ MORENO, J. Fundamentos del deporte: análisis de las estructuras del juego deportivo. 2. ed. Barcelona: INDE, 1998.

\section{${ }^{9}$ SANTANA, W. C. Atitudes táticas elementares para atacar e defender em futsal.} 2006. Disponível em: <http://www.pedagogiadofutsal.com.br/texto_036.asp>. Acesso em: 17 set. 2008 . 
${ }^{10}$ TANI, G.; CORREA, U. C. Esportes coletivos: alguns desafios quando abordados sob uma visão sistêmica. In: ROSE JUNIOR, D. (Org.). Modalidades esportivas coletivas. Rio de Janeiro: Guanabara Koogan, 2006. p. 15-23.

${ }^{11}$ LOZANO CID, J. et al. Táctica en alta competición. Madrid: Federación Madrileña de Futbol-Sala, 2002.

${ }^{12}$ SAAD, M. A. COSTA, C. Futsal: movimentações ofensivas e defensivas. Florianópolis: BookStore, 2001. 